\title{
RISK FACTORS OF ROAD TRAFFIC ACCIDENTS (RTA) IN CONTEXT OF BANGLADESH
}

\author{
JABBAR MA ${ }^{1}$, ISLAM MZ ${ }^{2}$, SULTANA R ${ }^{3}$, AKHTER SFU ${ }^{4}$
}

\begin{abstract}
:
Objective: To explore the risk factors related to road traffic accident in context of Bangladesh.

Design: This was a cross sectional type of descriptive study.

Settings: The study was conducted at emergency and casualty department of Dhaka Medical College Hospital (DMCH) and Sir Salimullah Medical College (SSMC) \& Mitford Hospital, Dhaka respectively.
\end{abstract}

Study Period: The study was conducted from July 2007 to June 2008.

Subjects: A total of 400 Road Traffic Accident (RTA) patients attended during data collection period of 3 months at Dhaka Medical College and Sir Salimullah Medical College (SSMC) \& Mitford Hospitals were consider as the study population.

Result: This study included 400 Road Traffic Accident (RTA) patients. Among them, 23.8\% patients due to accidents were related to truck accidents followed by bus (20.3\%) and CNG Taxi (11.3\%) respectively It has been revealed that frequency of accidents caused by new vehicles and old vehicles were almost equal (36.5\%) and $13.5 \%$ vehicle were overloaded when accidents happened. Fast speeds of the vehicles (62\%) were responsible for accidents. About $31 \%$ stated that even with normal speed accident was happened. About $44.8 \%$ accidents were caused due to collision with other vehicles as stated by the patients. Majority of the patients (52.8\%) stated that drivers were looked healthy, 17.8\% drunker and 5.5\% looked drowsy when they drove vehicles during accident. Majority (55\%) of them drove in wrong side of the road. In 78.3\% cases, there was no traffic signal and though available, 39.1\% driver did not follow traffic signal. About 25\% patients stated that defective road is the factor of causation of accidents. Majority (76.75\%) of the patients opined that accident was happened during day time and in sufficient light (66\%). Weather was foggy stated by $16 \%$ patients. Only $6.75 \%$ victims used protective measure during accidents.

Conclusion: This study was conducted with a view to explore the risk factors related to road traffic accident. Nevertheless, it is not feasible to draw a concrete conclusion. But on the basis of this study findings, it may be stated that a greater part of Road Traffic Accidents (RTA) can be prevented by specific preventive measures and also taking personal precautions. It is also to be concluded that countywide wide mass scale study should be carried out in this specific emerging field to combat road traffic accidents as a major public health issue.

Key words: Road traffic accidents (RTA), Risk Factors.

J Dhaka Med Coll. 2009; 18(2) : 161-165

\section{Introduction:}

Accident has been defined as an unexpected, unplanned occurrence, which involves injury. ${ }^{1}$ Road accident is treated as a major epidemic of non-communicable disease in the present century. They are no longer considered accidental rather than they are part of the price we pay for technological progress. ${ }^{2}$
Accident constitutes variable epidemics and imposes mortality, morbidity and disability burden to the victims. RTAs are the fourth in order among the leading causes of total death. Accidents are responsible for approximately 10\% of all global deaths and $16 \%$ of global disabilities. Common victims of death caused by accidents are young age groups (10-24 years). ${ }^{3}$

1. Professor and Head, Department of Community Medicine, Dhaka Medical College, Dhaka.

2. Assoc. Professor, Department of Community Medicine, NIPSOM, Dhaka.

3. Lecturer, Dept. of Community Medicine, Dhaka Medical College, Dhaka.

4. Assoc. Prof (C.C.), On Lien: Asstt. Prof. Dept. of Community Health \& Family Medicine, International Islamic University Malaysia (IIUM), Malaysia.

Correspondence: Md. Abdul Jabbar 
WHO studies show that road traffic accidents account for $2.5 \%$ of the total deaths. Globally, RTAs result in an estimated 1.2 million deaths and a further 50 million injuries per year. ${ }^{3}$ It is reported that for every death caused by accident, there are as many as 30 to 40 minor injuries and 10-15 serious injuries requiring long periods of expensive nursing care and treatment. ${ }^{4,5}$

Statistics has shown that mortality in road traffic accidents is very high among young adults in their prime and who constitute the work force ${ }^{6,7}$ Innocent children are often direct victims of road mishaps and many become orphaned from these accidents. A study of accounts of accidents in the literature reveals some responsible factors. ${ }^{8,9}$ The risk factors involved in RTA's include the person, the machine, environment and the road. While most RTA's related to motor vehicles, bicycle or pedestrian. ${ }^{10} \mathrm{~A}$ pedestrian may fall into an open manhole or drainage and may be a victim of RTA. ${ }^{11}$

Man may neglect to ensure that the machine is roadworthy and in good shape. In some countries, it is unlawful to transport children as front seat passengers. It is also an offence to have a passenger in the car without the safety belts fastened. ${ }^{12,13,14}$ A few road traffic injuries occurred among pedestrians and cyclists for dangerous road conditions but excluding motorized vehicles. ${ }^{15}$ In number and severity, most road traffic accidents involve motor vehicles. Road conditions are important etiologic factors in RTA worldwide. Rural roads tend to pose special and additional hazards. ${ }^{16}$ In context of the developing country like Bangladesh; the defective road is a major factor for RTA. Many roads become death traps. Often roads are blocked by broken-down vehicles or by garbage dumped. In some countries, more than $10 \%$ of the hospital beds are occupied by patients injured in road accidents. ${ }^{17}$

The Statistical Year Book (2000) contains figures from 1987 to 2000 . The total number of accidents ranged from 1,521 in 1987 to 3,419 in 2000. Of these, the causalities in 1987 were 1,156 , which raised by $164 \%$ in 2000 . A recent study, based on household survey data, concluded that the actual number of road deaths occurring in Bangladesh is at over 8,000 and currently estimated to be 12,786 , which is at least 2.6-4.2 times greater than that included in official statistics. Road traffic accidents pose an adverse economic impact on other members of the families. ${ }^{18}$

From the above discussion it is now crystal clear that study on the risk factors for road traffic accident is very much relevant, which will help us for drawing attention on the facts liable for this giant burden on our national development, economy and public safety.

\section{Materials \& Methods:}

It was a cross sectional type of descriptive study conducted with the objective to explore the risk factors related to road traffic accident in context of Bangladesh at emergency and casualty department of Dhaka Medical College Hospital (DMCH) and SSMC \& Mitford Hospital. These were selected purposively for data collection. The study was conducted for the period from July 2007 to June 2008. A total of 400 RTA patients were included and data was collected from the patients by face to face interview and by using a semi-structured questionnaire. Data were coded and edited. Data entry and analysis was done by computer. Data were analyzed in relation to the objectives of the study and presented as tables and graphs.

\section{Results:}

Table-I showed that truck (23.8\%) was found mainly responsible for accidents followed by bus (20.3\%) and CNG Taxi (11.3\%). Frequency of accidents caused by new vehicle and old vehicle were about of equal (36.5\%) and $13.5 \%$ vehicle were overloaded when accidents happened. About $62 \%$ cases was fast speed of the vehicle's were responsible for accidents. Even with usual speed (31.3\%) accident happened. About 44.8\% accidents were caused due to collision with other vehicle. 
Table-I Agent factors of Accident

\begin{tabular}{lcc}
\hline Vehicle & Number & Percentage \\
\hline Type - Truck & 95 & 23.8 \\
$\quad$ Bus & 81 & 20.3 \\
$\quad$ CNG Taxi & 45 & 11.3 \\
Others & 179 & 44.75 \\
Condition - New & 146 & 36.5 \\
Old & 146 & 36.5 \\
Overloaded & 54 & 13.5 \\
Very old & 38 & 09.5 \\
Others & 16 & 04.0 \\
Speed -Fast & 247 & 61.8 \\
Usual & 125 & 31.3 \\
Mixed fast \& Slow & 04 & 01.0 \\
Slow & 24 & 06.0 \\
Mode of accident - & 79 & 19.8 \\
Vehicle itself & & \\
Collision with & 179 & 44.8 \\
other vehicle & & \\
Due to deformity & 19 & 04.8 \\
of road & & \\
Collision with & 09 & 02.3 \\
animal & & \\
Others & 114 & 28.5 \\
\hline
\end{tabular}

Table-II: Showed that $52.8 \%$ drivers were looked healthy, $17.8 \%$ looked drunk and 5.5\% looked drowsy when they drove the vehicle at the time of accident. Majority (55\%) of them drove in wrong way of the road. In $78.3 \%$ cases there was no traffic signal and though available, $39.1 \%$ driver did not follow traffic signal.

Table-II

Host factors of Accident

\begin{tabular}{lcc}
\hline Host (Driver) & Number & Percentage \\
\hline Health condition- & 211 & 52.7 \\
$\quad$ Looking Healthy & & \\
$\quad$ Looking Drunk & 71 & 17.8 \\
$\quad$ Looking Drowsy & 22 & 05.5 \\
$\quad$ Others & 96 & 24.0 \\
Way of driving - & & \\
$\quad$ Right way & 158 & 39.5 \\
$\quad$ Wrong way & 220 & 55.0 \\
$\quad$ Others & 22 & 05.5 \\
Traffic signal - & & \\
$\quad$ Available & 87 & 21.8 \\
$\quad$ Not available & 313 & 78.3 \\
Violation of & & \\
Traffic signal - & & \\
$\quad$ Yes & 34 & 39.1 \\
$\quad$ No & 53 & 60.9 \\
\hline
\end{tabular}

Table 3 showed that $24.7 \%$ patients stated that road condition was defective. Majority $(76.75 \%)$ of them opined that an accident was happened during day time in sufficient light (66\%). Weather was foggy stated by $16 \%$ patients. Only $6.75 \%$ victims used protective measure during accidents.

Table-III

Environmental factors of Accident

\begin{tabular}{lcc}
\hline Factors & Number & Percentage \\
\hline Road condition - & & \\
Defective & 99 & 24.75 \\
Narrow & 81 & 20.25 \\
Faulty road & 49 & 12.25 \\
breaker & & \\
Poor lighting & 50 & 12.5 \\
$\quad$ Good & 121 & 30.25 \\
Time of accident - & & \\
$\quad$ Day time & 307 & 76.75 \\
$\quad$ Evening & 264 & 66.0 \\
$\quad$ Night & 08 & 02.0 \\
Weather condition - & & \\
$\quad$ Rainy & 47 & 11.8 \\
Foggy & 64 & 16.0 \\
Cloudy & 36 & 09.0 \\
Others & 253 & 63.3 \\
Use of protective & & \\
measures - & & \\
$\quad$ Helmet & 14 & 3.5 \\
$\quad$ Safety belt & 13 & 3.25 \\
$\quad$ Not used & 373 & 93.25 \\
\hline
\end{tabular}

\section{Discussion:}

The study entitled "Risk Factors for Road Traffic Accident Patients Attended Tertiary Level Hospitals of Bangladesh" results showed that truck were responsible for most $(23.8 \%)$ of the accidents, $36.5 \%$ vehicles faced accidents was new and another $36.5 \%$ was old. Most $(76.75 \%)$ of the accidents occurred in daytime as shown by this study but study conducted in NITOR showed it as 69\%. ${ }^{19}$ About 55\% respondents stated that vehicles were driven in a wrong way and $78 \%$ respondents stated there were no traffic signals in the road. Among those who stated that there was traffic signal, about $70 \%$ of them stated that the driver was not following the traffic rule. It has been seen that high 
burden of RTA was due to poor enforcement of traffic safety regulations. The present study showed that significant part of RTA occurred due to defective road conditions $(24.75 \%)$ followed by narrow road (20.25\%), faulty road breaker $(12.25 \%)$ respectively. A remarkable part of RTA took place in foggy $(16 \%)$, rainy $(11.8 \%)$ and cloudy $(9.0 \%)$ weather and in poor light (32\%).

A relevant study revealed that buses are often second-hand imports from wealthier countries and lack up-to-date safety features. Passenger cars tend to be older and do not have air bags, collapsible steering columns or other crashprotective features. In addition, vehicles are not as well maintained in developing countries. ${ }^{20}$ Poor road and land-use planning often leads to a deadly mix of high-speed through traffic, heavy commercial vehicles, MTWs, pedestrians and bicyclists on developing-country roads. Accommodations for vulnerable road users, such as sidewalks and bicycle lanes, are rare. ${ }^{21}$

The study showed that about $18 \%$ cases the drivers were drunker. Considering speed of vehicle, it was found that fast speed of a vehicle is responsible in majority accidents $(61.8 \%)$ and at the time of accident $13.5 \%$ vehicle was overloaded. Even with usual speed about 31\% accidents were also occurred. In respect of use protective measures the study showed that most of them i.e. 373 (93.25\%) patients / victim of accident did not used any protective measure.

ADB conducted study concluded that speeding dramatically increases crash risk and crash severity. It has been shown that an increase of $1 \mathrm{kph}$ in mean traffic speed results in a 3\% increase in the incidence of injury crashes and a $4-5 \%$ increase in fatal crashes. ${ }^{21}$ According to European transport society, failure to use seatbelts dramatically increases crash severity. Seatbelt use reduces crash death risk by $40-65 \%$, moderate and severe injuries by $43-65 \%$ and all injuries from $40-50 \% .^{22}$ The study carried out by Servadei F showed similar relevant findings and recommended that Bicycle helmet use reduces head injury risk from $63-88 \% .^{23}$

\section{Conclusion:}

This study was conducted with a view to explore the risk factors related to road traffic accident. It was observed that majority of the accidents happened in day time and caused mostly by truck followed by bus. Most of the victims were passengers, pedestrians and drivers. It was found that greater portion of the RTA occurred due to collusion between two vehicles followed by defective road. A significant number of accidents took place during bad weather. More than half of the accidents occurred due to wrong side driving. On the basis of the findings, it may be recommended that a greater part of RTA can be prevented by imposing specific protective measures and taking personal precautions and Traffic rules.

\section{References:}

1. Hogarth J. Glossary of Health Care Technology. World Health Organization (WHO), Copenhagen 1978.

2. World Health Organization (WHO) 1957. Technical Report Serial No. 118.

3. Director General, World Health Organization (WHO). World Health Report 2004.

4. Ravindra NG. Road traffic accidents are a preventable scourge. Swasth Hind 1982; 26(11): 272 .

5. Anonymous. Road Accidents: The Unnecessary Epidemic? BMJ. 1978; 1: 547.

6. Balogun JA, Abereoje OK. Pattern of road traffic accident cases in a Nigerian university teaching hospital between 1987 and 1990. J Trop Med Hyg 1992; 95: 23-29.

7. Luby S, Hassan I, Jahangir N, Rizvi N, Farooqi M, Ubaid S, Sadruddin S. Road J Trop Med Public Health 1997; 28: 395-398.

8. Odero W. Alcohol-related road traffic injuries in Eldoret, Kenya. East Afr Med J 1998; 75: 708711 .

9. Posada J, Ben-Michael E, Herman A, Kahan E, Richter E. Death and injury from motor vehicle crashes in Colombia. Rev Panam Salud Publica 2000; 7: 88-91.

10. Stutts JC, Hunter WW. Motor vehicle and roadway factors in pedestrian and bicyclist injuries: an examination based on emergency department data. Accid Anal Prev 1999; 31: 505-514.

11. Chapple CR. Urethral Injury. BJU International 2000; 86: 318-326. 
12. Mao Y, Zhang J, Robbins G, Clarke K, Lam M, Pickett W. Factors affecting the severity of motor vehicle traffic crashes involving young drivers in Ontario. Inj Prev 1997; 3: 183-189

13. Tingvall C. Children in cars. Some aspects of the safety of children as car passengers in road traffic accidents. Acta Paediatr Scand Suppl 1987; 339: $1-35$.

14. McCarthy M. The benefit of seat belt legislation in the United Kingdom. J Epidemiol Community Health 1989; 43: 218-222.

15. Luby S, Hassan I, Jahangir N, Rizvi N, Farooqi M, Ubaid S, Sadruddin S. Road J Trop Med Public Health 1997; 28:395-398.

16. Street JT, Winter D, Buckley S, Nicholson P, Twomey A. Trauma on rural roads: the role of a peripheral hospital. Injury 1999; 30: 337-340.
17. Bangladesh Bureau of Statistics (BBS). Statistical Pocket Book 2004.

18. Report of Transport Research Laboratory. United Kingdom, 2003.

19. Khatun M, Ali SMI, Rahman AKMF, Talukder SN, Ashrafuddin M. Characteristics of RTA victims admitted in NITOR, Dhaka. J Dhaka Med Col. 2006; 15(1): 28-33.

20. Vinand NM, Michael RR. The neglected epidemic: Road traffic injuries in developing countries. BMJ 2002; 324(7346): 1139 - 1141 .

21. Private conversation with Charles Melhuish. Transport Sector Specialist, Asian Development Bank, 2002.

22. Forgiving roadsides. Brussels, European Transport Safety Council, 1998.

23. Servadei F et al. Effect of Italy's motorcycle helmet law on traumatic brain injuries. Inj Prev. 2003; 9: 257-260. 